\title{
Astragaloside IV prevents high glucose-induced podocyte apoptosis via downregulation of TRPC6
}

\author{
XING-MEI YAO ${ }^{1 *}$, YU-JUN LIU ${ }^{1 *}$, YUN-MAN WANG ${ }^{1}$, HAO WANG $^{1}$, BING-BING ZHU $^{1}$, YONG-PING LIANG ${ }^{1}$, \\ WEI-GUO YAO ${ }^{1}$, HUI YU ${ }^{1}$, NIAN-SONG WANG ${ }^{2}$, XUE-MEI ZHANG ${ }^{3}$ and WEN PENG ${ }^{1}$ \\ ${ }^{1}$ Department of Nephrology, Putuo Hospital, Shanghai University of Traditional Chinese Medicine, Shanghai 200062; \\ ${ }^{2}$ Department of Nephrology and Rheumatology, Sixth People's Hospital Affiliated to Shanghai Jiaotong University, \\ Shanghai 200233; ${ }^{3}$ Department of Pharmacology, School of Pharmacy, Fudan University, Shanghai 201203, P.R. China
}

Received May 21, 2015; Accepted February 15, 2016

DOI: $10.3892 / \mathrm{mmr} .2016 .5167$

\begin{abstract}
Diabetic nephropathy (DN) is one of the most important causes of end-stage renal disease. Astragaloside IV (AS-IV) is a saponin isolated from Astragalus membranaceus, which possesses various pharmacological activities. AS-IV prevents podocyte apoptosis and ameliorates renal injury in DN; however, few studies have focused on its effects on ion channels. The transient receptor potential channel 6(TRPC6) is an important $\mathrm{Ca}^{2+}$-permeable ion channel in podocytes, which is involved in high glucose (HG)-induced podocyte apoptosis. The aim of the present study was to investigate whether AS-IV prevented HG-induced podocyte apoptosis via TRPC6. Cultured podocytes were pre-treated with 10,20 or $40 \mu \mathrm{M}$ AS-IV for $1 \mathrm{~h}$ prior to HG exposure for $24 \mathrm{~h}$. Apoptosis, cell viability, expression of TRPC6, nuclear factor of activated $\mathrm{T}$ cells (NFAT2) and B-cell lymphoma 2-associated X protein (Bax), as well as the intracellular $\mathrm{Ca}^{2+}$ concentration were subsequently analyzed. The results indicated that HG induced podocyte apoptosis and upregulation of TRPC6, and increased intracellular $\mathrm{Ca}^{2+}$. Furthermore, enhanced NFAT2 and Bax expression was detected. Conversely, AS-IV protected HG-induced podocyte apoptosis, downregulated TRPC6 expression and suppressed intracellular $\mathrm{Ca}^{2+}$ in HG-stimulated podocytes. AS-IV also suppressed NFAT2 and
\end{abstract}

Correspondence to: Dr Wen Peng, Department of Nephrology, Putuo Hospital, Shanghai University of Traditional Chinese Medicine, 164 Lanxi Road, Shanghai 200062, P.R. China

E-mail: pengwen_01@vip.sina.com

Dr Xue-Mei Zhang, Department of Pharmacology, School of Pharmacy, Fudan University, 826 Zhangheng Road, Shanghai 201203, P.R. China

E-mail: xuemzhang@fudan.edu.cn

*Contributed equally

Key words: astragaloside IV, transient receptor potential channel 6, nuclear factor of activated $\mathrm{T}$ cells, B-cell lymphoma 2-associated X protein, podocyte apoptosis, diabetic nephropathy
Bax expression. These results suggest that AS-IV may prevent HG-induced podocyte apoptosis via downregulation of TRPC6, which is possibly mediated via the calcineurin/NFAT signaling pathway.

\section{Introduction}

Diabetic nephropathy (DN) is a major complication of diabetes and a frequent cause of end-stage renal disease (1). The predominant pathological alterations associated with DN include mesangial expansion, podocyte loss, increased thickness of the basement membrane, and glomerular and tubular cell injury, resulting in glomerulosclerosis and interstitial fibrosis $(2,3)$. Hyperglycemia is key in renal cell injury and extracellular matrix overproduction in DN $(4,5)$.

Podocytes are terminally differentiated cells present on the outer surface of the glomerular basement membrane, which maintain the structure and function of the glomerular filtration barrier. Previous studies have demonstrated that podocyte injury is involved in the generation and progression of DN (6-8). Furthermore, a decrease in the number of podocytes in the glomeruli is the strongest predictor of DN progression $(7,8)$. Previous studies have indicated that apoptosis contributes to a reduction in podocytes, and high glucose (HG) induces podocyte apoptosis $(9,10)$.

Transient receptor potential channel 6 (TRPC6) is a member of the large TRP superfamily of nonselective cation channels. This superfamily comprises a group of six transmembrane domain-containing ion channels (11-13). It has been demonstrated that mutations in the TRPC6 channel result in familial focal segmental glomerulosclerosis (14). In addition, TRPC6 is involved in the physiological and pathophysiological roles of podocytes $(15,16)$, including $\mathrm{HG}$-induced podocyte apoptosis (17-19).

The downstream signaling of TRPC6 includes the activation of two calcium-dependent transcription factors, the nuclear factor of activated T cells (NFAT) and cAMP response element binding protein (20-23). NFAT is the substrate for calcineurin $(\mathrm{CaN})$ and belongs to the family of $\mathrm{Ca}^{2+}$-dependent transcription factors (24). In inactivated cells, NFAT transcription factors are highly phosphorylated and are located in the cytoplasm. NFAT is translocated to 
the nucleus upon dephosphorylation where it stimulates gene transcription. Previous studies have demonstrated that NFAT activation is associated with podocyte injury and glomerulosclerosis $(25,26)$. Excessive activation of the CaN/NFAT signaling pathway has been identified as a potential mechanism underlying TRPC6-induced renal disease, including podocyte injury $(27,28)$.

Astragalus membranaceus is a widely used traditional Chinese medicine, particularly in renal diseases. Its extracts are typically classified as saponins, polysaccharides or flavonoids (29). Astragaloside IV (AS-IV) is an active ingredient of Astragalus, which exerts numerous effects, including antihypertensive, positive inotropic, anti-inflammatory and immunoregulatory activities $(30,31)$. Previous studies have demonstrated that AS-IV prevents podocyte apoptosis and ameliorates renal injury in DN (32-34). However, few studies have determined an association between AS-IV and ion channels. The present study aimed to investigate whether AS-IV prevents HG-induced podocyte apoptosis via TRPC6, thus providing a possible novel therapeutic strategy for the clinical treatment of DN.

\section{Materials and methods}

Reagents. Polyclonal rabbit anti-TRPC6 antibody (cat. no. PAB13220) was purchased from Abnova (Taiwan) Corporation (Taipei, Taiwan), the polyclonal rabbit anti-B-cell lymphoma 2-associated X protein (Bax; cat. no. 2772) and monoclonal rabbit glyceraldehyde 3-phosphate dehydrogenase (GAPDH; cat. no. 2118) antibodies were purchased from Cell Signaling Technology, Inc. (Danvers, MA, USA), the polyclonal rabbit anti-NFAT2 antibody (cat. no. ab25916) and polyclonal rabbit anti-histone H3 (cat. no. ab18521) were obtained from Abcam (Cambridge, MA,USA), and the horseradish peroxidase (HRP)-conjugated goat anti-rabbit immunoglobulin G ( $\mathrm{IgG})$ antibody (cat. no. 7074) was purchased from Cell Signaling Technology, Inc. A nuclear and cytoplasmic extraction kit was purchased from Cayman Chemical Company (Ann Arbor, MI, USA), and a bicinchoninic acid (BCA) protein assay kit was from Pierce Biotechnology, Inc. (Rockford, IL, USA). Primers were synthesized by Sangon Biotech Co., Ltd. (Shanghai, China). RPMI-1640 medium and fetal bovine serum (FBS) were obtained from Hyclone (GE Healthcare Life Sciences, Logan, UT, USA), and interferon $-\gamma$ was obtained from Sigma-Aldrich (St. Louis, MO, USA).

Cell culture and treatment. Conditionally immortalized mouse podocytes were verified by Professor Mundel (Division of Nephrology, Massachusetts General Hospital, Harvard Medical School) and donated by Professor Hao Chuanming (Huashan Hospital, Fudan University, Shanghai, China). The cells were inoculated into flasks coated with collagen type I (Invitrogen; Thermo Fisher Scientific, Inc., Waltham, MA, USA), and were cultured at $33^{\circ} \mathrm{C}$ in RPMI-1640 medium supplemented with $10 \mathrm{U} / \mathrm{ml}$ recombinant mouse interferon- $\gamma$ and $10 \%$ FBS. Once the cells reached $85 \%$ confluence they were digested and passaged using $0.05 \%$ trypsin-EDTA. To induce differentiation, the podocytes were cultured at $37^{\circ} \mathrm{C}$ in the same medium deprived of interferon- $\gamma$ for 14 days. Differentiated podocytes were cultured for $24 \mathrm{~h}$ in RPMI-1640 medium containing $1 \% \mathrm{FBS}$ prior to exposure to the various experimental conditions. AS-IV (Shanghai Tauto Biotech Co., Ltd., Shanghai, China) was dissolved in dimethyl sulfoxide (DMSO) to produce a stock solution; the final DMSO concentration did not exceed $0.1 \%(\mathrm{v} / \mathrm{v})$. The cells were divided into the following groups: i) Normal glucose (NG) control group, in which the cells were incubated in RPMI-1640 containing $5 \mathrm{mM}$ glucose; ii) mannitol (MA) group, in which the cells were incubated in NG medium supplemented with $25 \mathrm{mM}$ D-mannitol as an osmotic control; iii) HG group, in which the cells were incubated in RPMI-1640 containing $30 \mathrm{mM}$ glucose; and iv) AS-IV + HG group, in which the cells were pre-incubated with AS-IV $(10,20$ or $40 \mu \mathrm{M})$ for $1 \mathrm{~h}$ and were then incubated in HG medium for $24 \mathrm{~h}$. All the glucose used in the present study was D-glucose and each reaction was repeated in triplicate.

\section{3-[4,5]-Dimethylthiazol-2,5-diphenyltetrazolium bromide} (MTT) assay. Podocyte viability was assessed by MTT assay. Cells were plated in a 96-well plate, $24 \mathrm{~h}$ after stimulation $20 \mu \mathrm{l}$ MTT was added (5 mg/ml; Sigma-Aldrich), the cells were cultured for $4 \mathrm{~h}$ and the supernatant was carefully discarded. DMSO $(50 \mu \mathrm{l})$ was added to dissolve the crystals and the absorbance was measured at a wavelength of $570 \mathrm{~nm}$ using a SpectraMax 190 microplate reader (Molecular Devices, LLC, Sunnyvale, CA, USA). The cell activity was calculated as follows: Inhibition rate $=(1-$ treated group/control group) $\mathrm{x} 100 \%$.

Apoptosis assay. The suspended cells were collected and centrifuged for $5 \mathrm{~min}$. The adherent cells were digested with EDTA-free trypsin and centrifuged at $800 \mathrm{x} \mathrm{g}$ for $10 \mathrm{~min}$. The cells were washed with cold phosphate-buffered saline (PBS), resuspended, and centrifuged at $800 \mathrm{x} g$ for a further $10 \mathrm{~min}$. Binding buffer $(1 \mathrm{X} ; 300 \mu \mathrm{l})$ was added and the cells were resuspended. Subsequently, $5 \mu \mathrm{l}$ Annexin V-fluorescein isothiocyanate (FITC; BioVision, Mountain View, CA, USA) was added to the cells, and the cells were agitated and incubated at room temperature in the dark for $15 \mathrm{~min}$. Propidium iodide (PI; $5 \mu \mathrm{l}$; Sigma-Aldrich) was added for staining and $200 \mu 11 \mathrm{X}$ binding buffer was added. The stained cells were analyzed for apoptosis using fluorescence-activated cell sorting with a FACSCalibur flow cytometer (BD Biosciences, Franklin Lakes, NJ, USA). Cells positive for Annexin V-FITC and negative for PI were considered to be apoptotic.

Reverse transcription-quantitative polymerase chain reaction (RT-qPCR). Total RNA was extracted from the treated cells using TRIzol ${ }^{\circledR}$ (Invitrogen; Thermo Fisher Scientific, Inc.), according to the manufacturer's protocol. Reverse transcription was performed at $37^{\circ} \mathrm{C}$ for $15 \mathrm{~min}$, then $85^{\circ} \mathrm{C}$ for $5 \mathrm{sec}$ using a One Step PrimeScript ${ }^{\circledR}$ cDNA Synthesis kit (Clontech; Takara Biotechnology Co., Ltd., Dalian, China) with $1 \mu$ RNA per reaction, and with a total reaction volume of $20 \mu \mathrm{l}$. To determine the quantity of mRNA, the cDNA was amplified by qPCR with SYBR ${ }^{\circledR}$ Premix Ex Taq ${ }^{\text {TM }}$ II (Takara Biotechnology Co., Ltd.) using an iCycler ${ }^{\circledR}$ thermal cycler (Bio-Rad Laboratories, Inc., Hercules, CA, USA). The qPCR reaction consisted of $12.5 \mu \mathrm{l} \mathrm{SYBR}{ }^{\circledR}$ Premix Ex Taq ${ }^{\mathrm{TM}}$ II, $1 \mu \mathrm{l}$ each of forward and reverse primers, $2 \mu \mathrm{l} \mathrm{cDNA}$, and made up to $25 \mu \mathrm{l}$ with 
distilled water. The PCR primer sequences were as follows: TRPC6, sense 5'-TGTACGGATTGTGGAGGCT-3', antisense 5'-GATTGGGGTCACATCGTG-3'; Bax, sense 5'-GCAAAC TGGTGCTCAAGGC-3', antisense 5'-GGTCCCGAAGTA GGAAAGG-3'; NFAT2, sense 5'-GCCCAGCGATGAGTA TGAA-3', antisense 5'-ATGCACCAGCACAGAACG-3'; and GAPDH, sense 5'-ACCACAGTCCATGCCATCAC-3' and antisense 5'-TCCACCACCCTGTTGCTGTA-3'. The housekeeping gene GAPDH served as the internal control for mRNA expression levels. PCR cycling conditions consisted of an initial denaturation $\left(95^{\circ} \mathrm{C}, 30 \mathrm{sec}\right)$, followed by 40 cycles of incubation at $95^{\circ} \mathrm{C}$ for $5 \mathrm{sec}$, then at $60^{\circ} \mathrm{C}$ for $30 \mathrm{sec}$. The relative expression levels of each group were measured using the $2^{-\Delta \Delta \mathrm{Cq}}$ method (35).

Protein extraction and western blot analysis. Podocytes subjected to the different experimental conditions were lysed with radioimmunoprecipitation assay lysis buffer (Beyotime Institute of Biotechnology, Haimen, China). The samples were centrifuged, and the supernatants were collected as the total cell extracts. Nuclear and cytoplasmic proteins from the cells were extracted using the nuclear and cytoplasmic protein extraction kit, according to the manufacturer's protocol. Protein concentration of the samples were then determined by BCA assay, and $50 \mu \mathrm{g}$ total protein was used for gel electrophoresis. Proteins were separated by $10 \%$ sodium dodecyl sulfate-polyacrylamide gel electrophoresis. Proteins were transferred to a polyvinylidene fluoride membrane (EMD Millipore, Billerica, MA, USA), blocked in 5\% bovine serum albumin at $37^{\circ} \mathrm{C}$ for $2 \mathrm{~h}$ and were subjected to immunoblot analysis with antibodies against TRPC6, NFAT2, Bax, histone H3 and GAPDH overnight at $4^{\circ} \mathrm{C}$. All antibodies were used at a working concentration of $1 \mathrm{mg} / \mathrm{ml}(1: 1,000)$ in PBS containing $5 \%$ nonfat milk powder. The blots were then incubated with HRP-conjugated goat anti-rabbit IgG (dilution, 1:5,000) for $1 \mathrm{~h}$ at room temperature and visualized using the Enhanced Chemiluminescence kit (EMD Millipore). Optical density of the bands was measured using a Bio-Rad Molecular Imager VersaDoc MP gel imaging system with Bio-Rad Quantity One software and corrected by reference to the optical density of GAPDH bands.

Immunofluorescence staining and fluorescence microscopy. To determine NFAT2 localization, podocytes were placed on cover slips in a six-well plate. Following exposure to the various treatments, the differentiated podocytes were fixed with $4 \%$ paraformaldehyde at room temperature for $15 \mathrm{~min}$. The cells were blocked with $5 \%$ bovine serum albumin (Abcam) for $30 \mathrm{~min}$ at room temperature and were then incubated with rabbit anti-NFAT2 overnight at $4^{\circ} \mathrm{C}$. Following three washes with PBS, the cells were incubated with the secondary antibody in the dark for $1 \mathrm{~h}$ at room temperature, washed three times with PBS, rinsed once with distilled water, and were then incubated with Hoechst 33342 (Anaspec, Fremont, CA, USA). The cells were inspected under an Olympus IX51 fluorescence microscope (Olympus Corporation, Tokyo, Japan).

Intracellular $\mathrm{Ca}^{2+}$ level assay. The podocytes were cultured in a 96-well fluorescence plate under routine conditions. After $24 \mathrm{~h}$, the cells were rinsed with Hank's balanced salt solution (HBSS; GE Healthcare Life Sciences) and were then incubated with Fluo-3/AM (final concentration, $5 \mu \mathrm{M}$; Invitrogen; Thermo Fisher Scientific, Inc.) in the dark for 45 min at $37^{\circ} \mathrm{C}$. The cells were centrifuged at $800 \mathrm{x} \mathrm{g}$ for $5 \mathrm{~min}$ at $37^{\circ} \mathrm{C}$, the medium was aspirated, and the cells were washed twice with $\mathrm{HBSS}$ and incubated for $15 \mathrm{~min}$ at $37^{\circ} \mathrm{C} . \mathrm{Ca}^{2+}$ labeling with Fluo-3/AM was detected at an excitation wavelength of $488 \mathrm{~nm}$ and an emission wavelength of $526 \mathrm{~nm}$ with an LSM 880 confocal microscope (Zeiss AG, Oberkochen, Germany).

Statistical analysis. Statistical analyses were conducted using SPSS 13.0 software (SPSS, Inc., Chicago, IL, USA). All data are presented as the mean \pm standard deviation. The statistical significance was evaluated using one-way analysis of variance and Newman-Keuls multiple comparisons post hoc analysis, and $\mathrm{P}<0.05$ was considered to indicate a statistically significant difference.

\section{Results}

$H G$ decreases podocyte viability, which is attenuated by $A S-I V$. To investigate the effects of AS-IV on the viability of HG-stimulated podocytes, an MTT assay was performed. As presented in Fig. 1A, exposure to HG for $24 \mathrm{~h}$ significantly inhibited the viability of podocytes by $20.19 \pm 4.26 \%$ $(\mathrm{P}=0.0006 ; \mathrm{n}=3)$. As expected, MA had no significant effect on podocyte viability, suggesting that the decreased cell viability in the HG group was not due to high osmolarity. Conversely, 20 or $40 \mu \mathrm{M}$ AS-IV significantly enhanced podocyte viability, and cell viability inhibition was reduced to $18.04 \pm 2.01 \%$ $(\mathrm{P}=0.03 ; \mathrm{n}=3)$ and $13.21 \pm 1.78 \%(\mathrm{P}=0.0008 ; \mathrm{n}=3)$, respectively, as compared with the HG group.

$H G$ induces podocyte apoptosis, which is inhibited by $A S-I V$. The effects of AS-IV on apoptosis were determined by flow cytometry. As presented in Fig. 1B, HG significantly increased the rate of podocyte apoptosis to $32.66 \pm 1.99 \%$ $(\mathrm{P}=0.0004 ; \mathrm{n}=3)$ and MA resulted in no significant change. AS-IV (20 or $40 \mu \mathrm{M})$ reduced the rate of podocyte apoptosis to $22.15 \pm 6.15 \%(\mathrm{P}=0.03 ; \mathrm{n}=3)$ and $15.09 \pm 0.57 \%(\mathrm{P}=0.0007$; $\mathrm{n}=3$ ), respectively, compared with the HG group.

AS-IV inhibits the upregulation of TRPC6 in HG-stimulated podocytes. To determine whether AS-IV reduces TRPC6 expression in HG-stimulated podocytes, the effects of different treatments were assessed by RT-qPCR and western blotting (Figs. 2 and 3). HG increased TRPC6 mRNA and protein expression levels by $151 \pm 0.37 \%$ and $89.2 \pm 13.4 \%$, respectively $(\mathrm{P}=0.0006$ and $\mathrm{P}=0.0007$, respectively; $\mathrm{n}=3)$. Conversely, treatment with 20 or $40 \mu \mathrm{M}$ AS-IV reduced the mRNA $(\mathrm{P}=0.02$, $\mathrm{n}=3 ; \mathrm{P}=0.0005, \mathrm{n}=3$, respectively) and protein expression levels of TRPC6 $(\mathrm{P}=0.01, \mathrm{n}=3 ; \mathrm{P}=0.0004, \mathrm{n}=3$, respectively; Figs. 2A, 3C and D).

$H G$ increases NFAT expression, which is suppressed by $A S-I V$. Using RT-qPCR and western blot analysis (Figs. 2 and 3), the mRNA and protein expression levels of NFAT2, a downstream protein in the TRPC6 signaling pathway, were determined. As presented in Figs. 2B, 3A and B, HG 
A

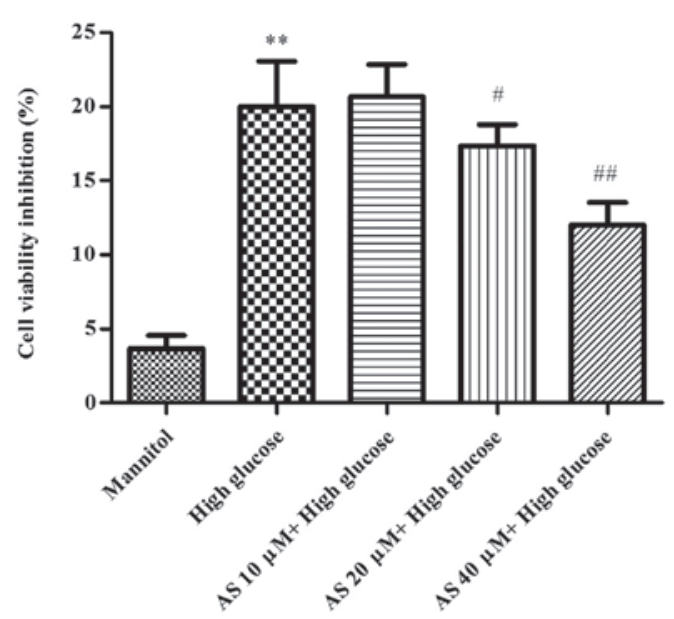

B

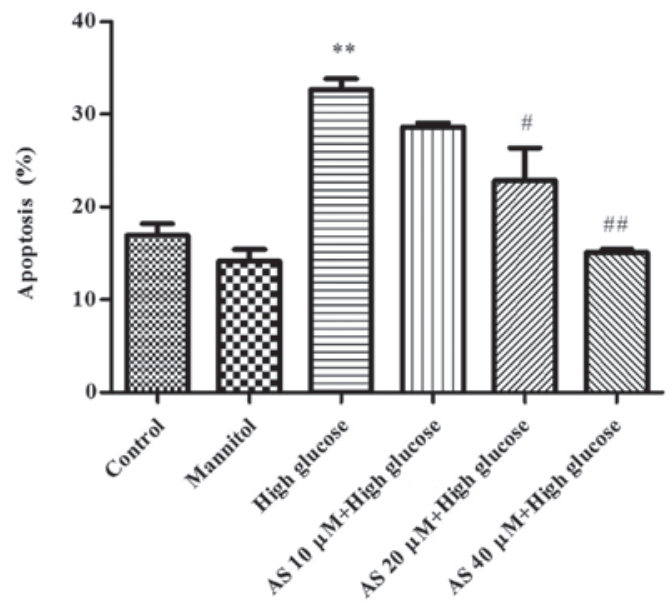

Figure 1. Histograms presenting the effects of different concentrations of AS on the cell viability and apoptosis of high glucose-stimulated podocytes. (A) Results are expressed as cell viability inhibition rate $(\% ; n=3)$. (B) Apoptosis was investigated by flow cytometric analysis of podocytes stained with Annexin V/propidium iodide. The results are presented as the apoptosis rate $(\% ; n=3) .{ }^{* *} \mathrm{P}<0.001$ vs. the normal glucose control. ${ }^{*} \mathrm{P}<0.05$, ${ }^{\# \prime} \mathrm{P}<0.001 \mathrm{vs}$. the high glucose group. Data are expressed as mean \pm standard deviation. AS, astragaloside IV.

significantly elevated NFAT2 mRNA expression levels by $182 \pm 0.33 \%(\mathrm{P}=0.0005 ; \mathrm{n}=3)$ and nuclear protein expression levels by $389.2 \pm 19.8 \%(\mathrm{P}=0.0004 ; \mathrm{n}=3)$, in addition to decreasing NFAT2 expression in the cytoplasm by $313.6 \pm 8.7 \%(\mathrm{P}=0.0005 ; \mathrm{n}=3)$; however, MA did not result in significant changes. Furthermore, the effects were suppressed by AS-IV, AS-IV (20 and $40 \mu \mathrm{M}$ ) decreased NFAT2 mRNA expression levels $(\mathrm{P}=0.04, \mathrm{n}=3 ; \mathrm{P}=0.0003$, $\mathrm{n}=3$, respectively), upregulated NFAT2 cytoplasmic protein expression levels $(\mathrm{P}=0.0004, \mathrm{n}=3$; and $\mathrm{P}=0.0002, \mathrm{n}=3$, respectively), and decreased NFAT2 nuclear protein expression levels $(\mathrm{P}=0.0002, \mathrm{n}=3$; and $\mathrm{P}=0.0001, \mathrm{n}=3$, respectively $)$ in a dose-dependent manner.

AS-IV inhibits Bax expression in HG-stimulated podocytes. To further investigate the prevention of podocyte apoptosis by AS-IV, alterations in Bax expression levels were observed (Figs. 2 and 3). HG upregulated Bax mRNA and protein expression levels by $203 \pm 0.01 \%$ and by $73.2 \pm 6.8 \%$ ( $P=0.0005$ and $\mathrm{P}=0.0001$, respectively; $\mathrm{n}=3$ ), respectively. Conversely,
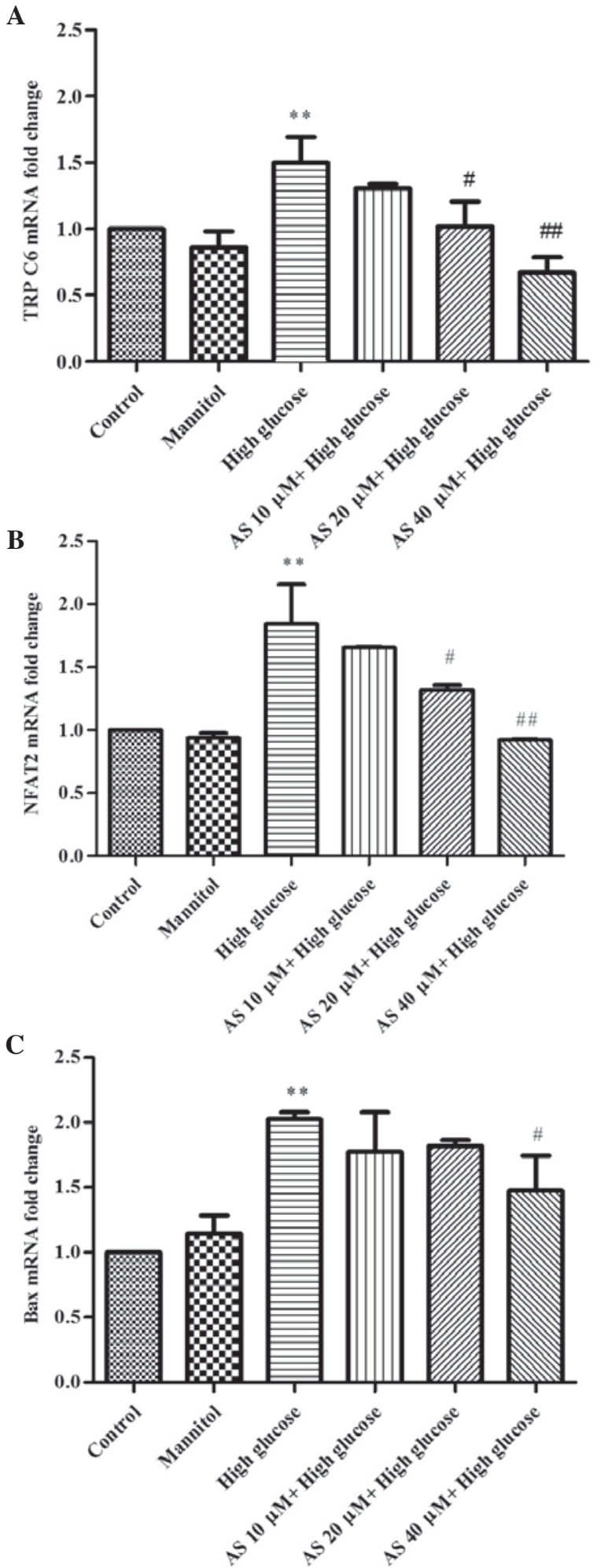

Figure 2. Representative graphs presenting the effect of AS on mRNA expression levels of TRPC6, NFAT2 and Bax in HG-stimulated podocytes. Effects of AS on mRNA expression levels of (A) TRPC6, (B) NFAT2 and (C) Bax. Data are presented as the mean \pm standard deviation $(n=3),{ }^{* *} \mathrm{P}<0.001$ vs. the normal glucose control. ${ }^{\#} \mathrm{P}<0.05,{ }^{\# \#} \mathrm{P}<0.001$ vs. the $\mathrm{HG}$ group. AS, astragaloside IV; HG, high glucose; TRPC6, transient receptor potential channel 6; NFAT2, nuclear factor of activated T cells; Bax, B-cell lymphoma 2-associated X protein.

$40 \mu \mathrm{M}$ AS-IV reduced Bax gene and protein expression levels ( $\mathrm{P}=0.03$ and $\mathrm{P}=0.01$, respectively; $\mathrm{n}=3$ ), as compared with the HG group (Fig. 2C, 3C and D). 
$\mathbf{B}$

A

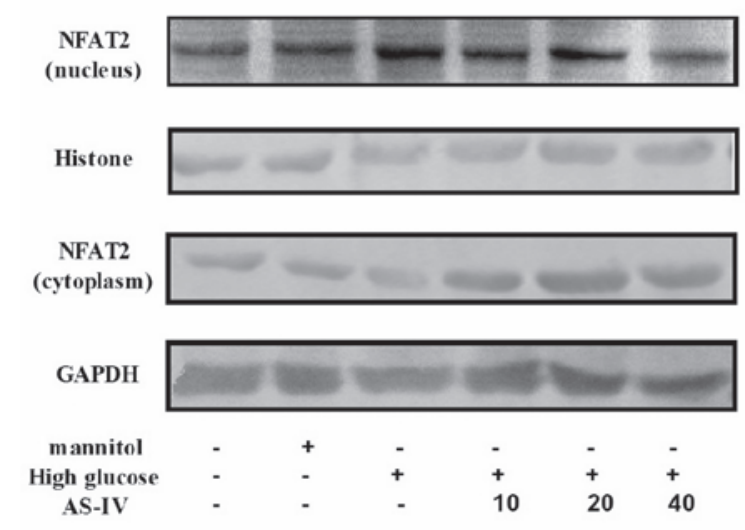

C

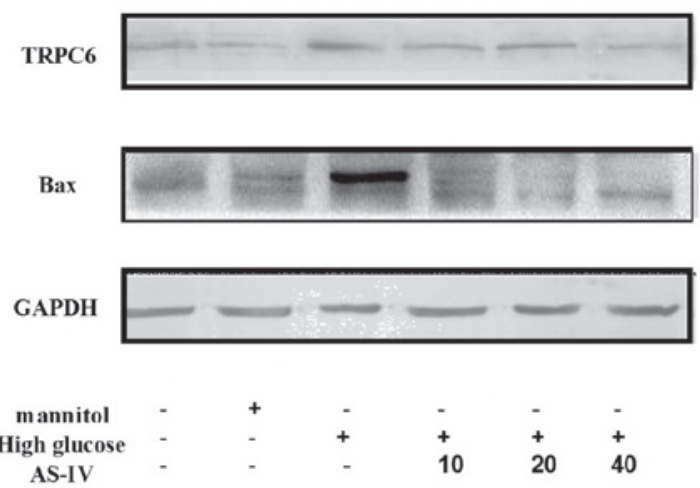

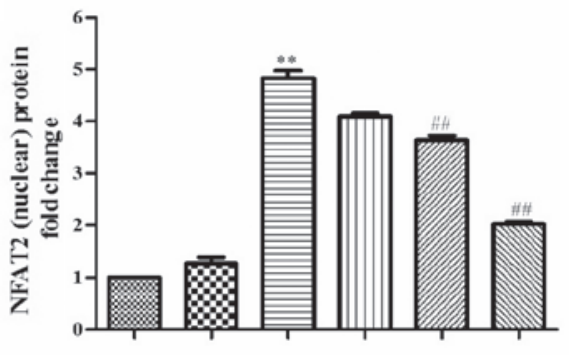

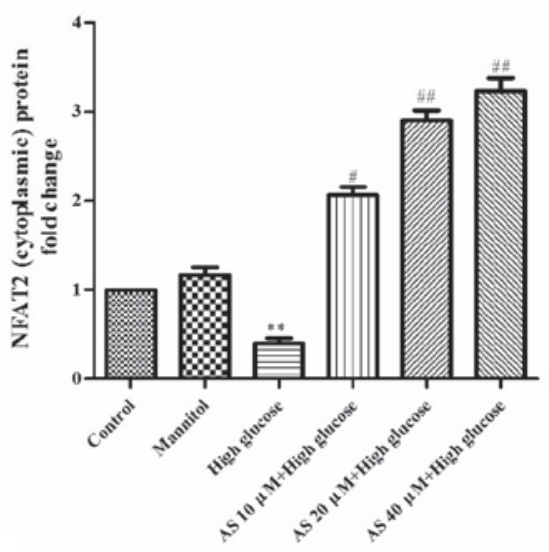

D
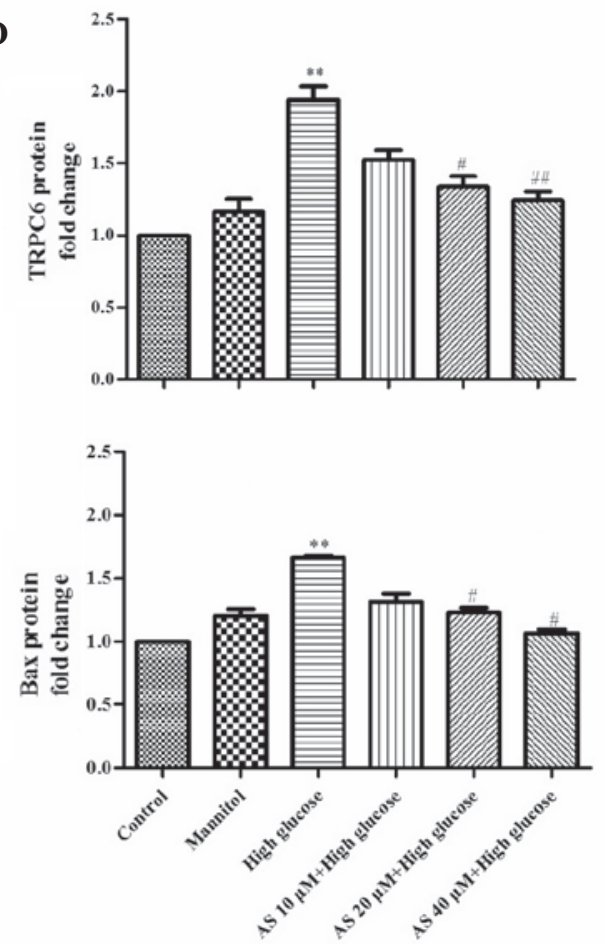

Figure 3. Representative graphs presenting the effect of AS-IV on protein expression levels of TRPC6, NFAT2 and Bax in HG-stimulated podocytes. (A) Representative western blot images demonstrating protein expression levels of nuclear and cytoplasmic NFAT2. (B) Quantitative analysis of the relative ratio of nuclear NFAT2 protein expression normalized to histone, and cytoplasmic NFAT2 protein expression normalized to GAPDH. (C) Representative western blot images demonstrating protein expression levels of TRPC6 and Bax. (D) Quantitative analysis of the relative ratio of TRPC6 and Bax protein expression normalized to GAPDH. Data are presented as the mean \pm standard deviation $(\mathrm{n}=3)$. ${ }^{* * *} \mathrm{P}<0.001$ vs. the normal glucose control. ${ }^{\#} \mathrm{P}<0.05$, ${ }^{\# \#} \mathrm{P}<0.001$ vs. the HG group. AS, astragaloside IV; HG, high glucose; TRPC6, transient receptor potential channel 6; NFAT2, nuclear factor of activated T cells; Bax, B-cell lymphoma 2-associated X protein; GAPDH, glyceraldehyde 3-phosphate dehydrogenase.

HG induces the nuclear translocation of NFAT2 in podocytes, which is suppressed by AS-IV. Immunoblotting experiments were performed to assess the nuclear translocation of NFAT2 in podocytes. As presented in Fig. 4, NFAT2 was predominantly distributed in the cytoplasm, and HG markedly increased NFAT2 nuclear accumulation in podocytes. However, $40 \mu \mathrm{M}$ AS-IV inhibited nuclear NFAT2 accumulation in the HG-stimulated podocytes. 

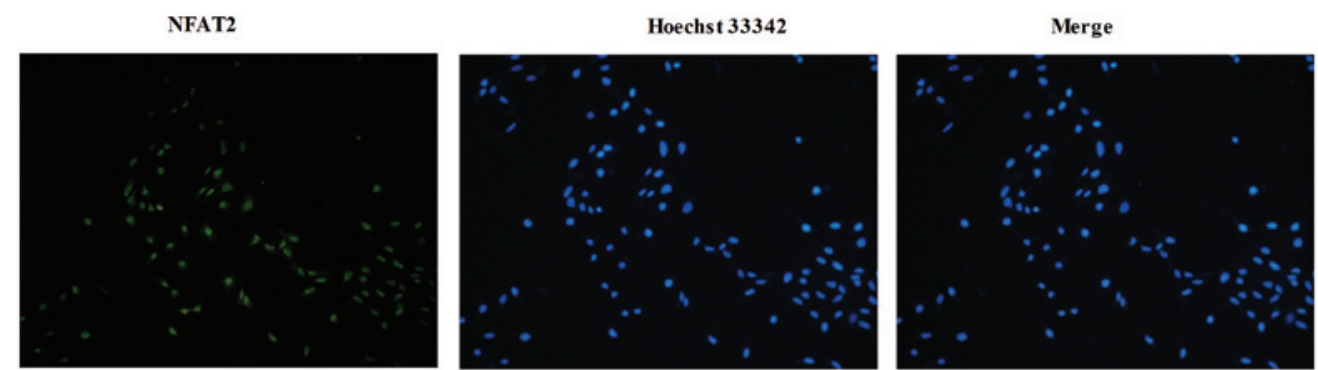

Control
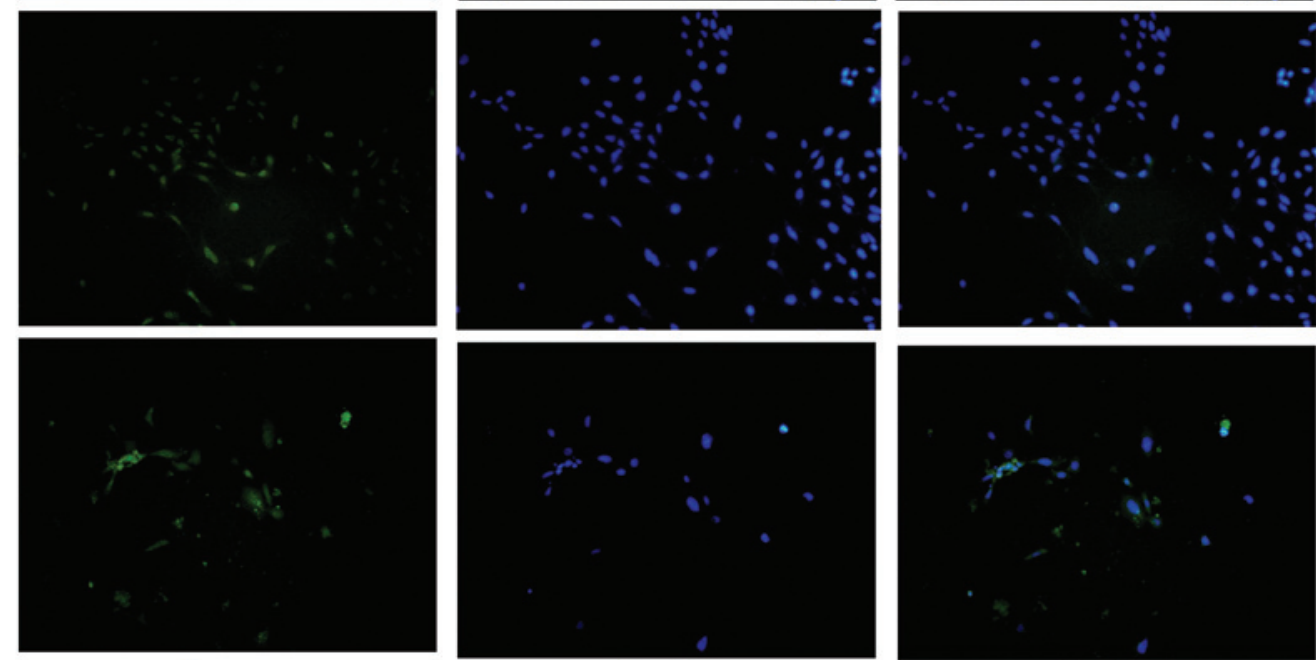

Mannitol
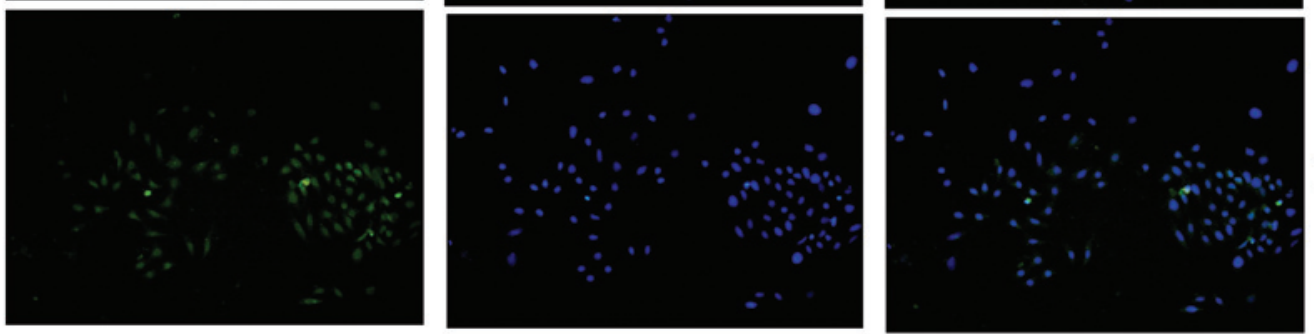

High glucose

AS $40 \mu \mathrm{M}$

+ High glucose

Figure 4. AS-IV suppressed the nuclear localization of NFAT2 in high glucose-stimulated podocytes. To assess the nuclear translocation of NFAT2 in podocytes, the effects were observed by inverted fluorescence microscopy. Confocal images of podocytes demonstrated the distribution of NFAT2 expression (green) and Hoechst 33342 -stained nuclei (blue). AS-IV, astragaloside IV; NFAT2, nuclear factor of activated T cells.

$H G$ increases the intracellular $\mathrm{Ca}^{2+}$ concentration in cultured podocytes, which is attenuated by AS-IV. To measure the changes in intracellular $\mathrm{Ca}^{2+}$ concentration in podocytes, the levels of $\mathrm{Ca}^{2+}$ labeled with Fluo-3/AM were determined by confocal laser scanning microscopy. The results demonstrated that $\mathrm{HG}$ treatment, but not MA treatment, significantly increased the $\mathrm{Ca}^{2+}$ level to $0.58 \pm 0.08 \%(\mathrm{P}=0.01 ; \mathrm{n}=3)$ in cultured podocytes. Treatment with $40 \mu \mathrm{M}$ AS-IV reduced the intracellular $\mathrm{Ca}^{2+}$ influx level to $0.48 \pm 0.07 \%$ in the HG-stimulated podocytes ( $\mathrm{P}=0.02 ; \mathrm{n}=3$; Fig. 5$)$.

\section{Discussion}

The present study is, to the best of our knowledge, the first to demonstrate that AS-IV prevents glucose-induced apoptosis of podocytes via ion channels. Upregulation of TRPC6 expression and increased intracellular $\mathrm{Ca}^{2+}$ levels in HG-stimulated podocytes were observed. In addition, it was demonstrated that TRPC6 was involved in the HG-induced apoptosis of podocytes. AS-IV significantly attenuated the HG-induced apoptosis of podocytes and induced a significant decrease in

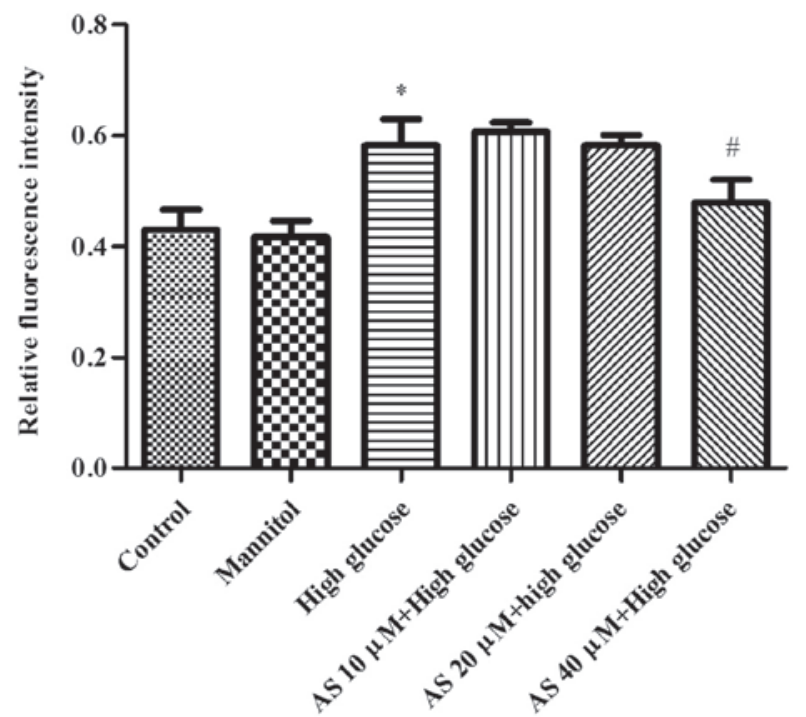

Figure 5. Measurement of intracellular $\mathrm{Ca}^{2+}$ concentration in the podocytes The results were expressed as mean relative fluorescence intensity \pm standard deviation ( $\mathrm{n}=3$ ). ${ }^{*} \mathrm{P}<0.05$ vs. the normal glucose control, ${ }^{\#} \mathrm{P}<0.05$ vs. the high glucose group. AS, astragaloside IV. 
TRPC6 expression and intracellular $\mathrm{Ca}^{2+}$ levels. Furthermore, AS-IV inhibited the activation of NFAT2, a downstream protein of TRPC6. AS-IV prevented the HG-induced apoptosis of podocytes via the downregulation of TRPC6, which was possibly mediated via the CaN/NFAT signaling pathway.

DN is an important and common complication of type 1 and type 2 diabetes, which results in end-stage renal disease (1). Podocyte apoptosis is key in the generation and progression of DN (6-8). Therefore, the prevention or inhibition of podocyte apoptosis may be a promising therapeutic strategy for the treatment of DN.

Podocytes express a family of nonselective cation channels termed TRPC that may contribute to calcium influx (15). TRPC6, one of the important $\mathrm{Ca}^{2+}$-permeable ion channels in podocytes, is closely associated with hereditary and acquired kidney diseases $(36,37)$. Numerous studies have demonstrated that TRPC6 is involved in cytoskeletal rearrangement, NFAT-dependent transcription, and apoptosis in podocytes (16,27,37-39). Recent investigations have demonstrated that HG increases TRPC6 expression in podocytes and that TRPC6 is involved in HG-induced podocyte apoptosis (17-19). In the present study, HG was observed to induce podocyte apoptosis and significantly increase TRPC6 mRNA and protein expression, and intracellular $\mathrm{Ca}^{2+}$ in podocytes. Exposure to MA had no significant effects, suggesting that the changes as a result of $\mathrm{HG}$ did not result from high osmolarity. These results were also consistent with those of previous studies (17-19).

NFAT2, which is a downstream protein of TRPC6, was also investigated. The NFAT transcription factors are well-researched $\mathrm{CaN}$ substrates and the major regulators of transcription in response to $\mathrm{Ca}^{2+} / \mathrm{CaN}$ signaling $(40,41)$. It has been demonstrated that the TRPC6/CaN/NFAT signaling pathway is involved in renal diseases, such as in podocyte injury $(27,28)$, and that HG-induced podocyte apoptosis is mediated via the CaN/NFAT2/Bax signaling pathway (42). Results from the present study indicated that HG induced NFAT2 nuclear translocation in podocytes. Furthermore, in the present study, Bax, an important indicator of apoptosis $(43,44)$, was observed to be activated in response to HG stimulation in podocytes.

AS-IV is considered a characteristic active saponin compound that mediates numerous pharmacological properties of Astragalus (29). Increasing evidence suggests that AS-IV has renal protective roles in DN, including attenuating podocyte injury and ameliorating podocyte apoptosis via anti-inflammatory signaling pathways, or inhibiting oxidative stress (32-34). Although TRPC6 participates in $\mathrm{HG}$-induced podocyte apoptosis, the protective role of AS-IV in ion channels remains to be elucidated. In the present study, AS-IV was demonstrated to inhibit podocyte apoptosis induced by HG, downregulate TRPC6, NFAT2 and Bax expression levels, and suppress intracellular $\mathrm{Ca}^{2+}$ levels in HG-stimulated podocytes.

In conclusion, these results demonstrated that AS-IV prevented HG-induced podocyte apoptosis via the downregulation of TRPC6, which was possibly mediated by the CaN/NFAT signaling pathway. These findings provide novel insights into the treatment of DN with AS-IV. There were, however, certain limitations to the present study. Although there are a number of subtypes of TRPC, TRPC6 was focused on in the current study. Changes in TRPC6 expression do not guarantee the involvement of this signaling pathway during cell injury and protection. Therefore, in a future investigation, the use of a more specific inhibitor or a genetic method to knockdown TRPC6 is required.

\section{Acknowledgements}

The present study was supported by the General Medicine of Key Discipline Construction Project, State Administration of Traditional Chinese Medicine of the People's Republic of China (grant no. 2013PT210), and the Budget Project (grant no. 2013JW59) and the Putuo Hospital Project, Shanghai University of Traditional Chinese Medicine (grant no. 2013PT028).

\section{References}

1. Collins AJ, Foley RN, Chavers B, Gilbertson D, Herzog C, Johansen K, Kasiske B, Kutner N, Liu J, St Peter W, et al: United States Renal Data System 2011 Annual Data Report: Atlas of chronic kidney disease \& end-stage renal disease in the United States. Am J Kidney Dis 59 (Suppl 1): e1-e420, 2012.

2. Hovind P, Rossing P, Tarnow L, Smidt UM and Parving HH: Progression of diabetic nephropathy. Kidney Int 59: 702-709, 2001.

3. Parving HH: Diabetic nephropathy: Prevention and treatment. Kidney Int 60: 2041-2055, 2001.

4. Kanwar YS, Wada J, Sun L, Xie P, Wallner EI, Chen S, Chugh S and Danesh FR: Diabetic nephropathy: Mechanisms of renal disease progression. Exp Biol Med (Maywood) 233: 4-11, 2008.

5. Ban CR and Twigg SM: Fibrosis in diabetes complications: Pathogenic mechanisms and circulating and urinary markers. Vasc Health Risk Manag 4: 575-596, 2008.

6. Wiggins RC: The spectrum of podocytopathies: A unifying view of glomerular diseases. Kidney Int 71: 1205-1214, 2007.

7. Drummond K and Mauer M; International Diabetic Nephropathy Study Group: The early natural history of nephropathy in type 1 diabetes: II. Early renal structural changes in type 1 diabetes. Diabetes 51: 1580-1587, 2002.

8. Pagtalunan ME, Miller PL, Jumping-Eagle S, Nelson RG, Myers BD, Rennke HG, Coplon NS, Sun L and Meyer TW: Podocyte loss and progressive glomerular injury in type II diabetes. J Clin Invest 99: 342-348, 1997.

9. Schiffer M, Bitzer M, Roberts IS, Kopp JB, ten Dijke P, Mundel P and Böttinger EP: Apoptosis in podocytes induced by TGF-beta and Smad7. J Clin Invest 108: 807-816, 2001.

10. Susztak K, Raff AC, Schiffer M and Böttinger EP: Glucose-induced reactive oxygen species cause apoptosis of podocytes and podocyte depletion at the onset of diabetic nephropathy. Diabetes 55: 225-233, 2006.

11. Venkatachalam K and Montell C: TRP channels. Annu Rev Biochem 76: 387-417, 2007.

12. Montell C: The TRP superfamily of cation channels. Sci STKE 2005: re3, 2005.

13. Ramsey IS, Delling M and Clapham DE: An introduction to TRP channels. Annu Rev Physiol 68: 619-647, 2006.

14. Winn MP, Conlon PJ, Lynn KL, Farrington MK, Creazzo T, Hawkins AF, Daskalakis N, Kwan SY, Ebersviller S, Burchette JL, et al: A mutation in the TRPC6 cation channel causes familial focal segmental glomerulosclerosis. Science 308: 1801-1804, 2005

15. Dryer SE and Reiser J: TRPC6 channels and their binding partners in podocytes: Role in glomerular filtration and pathophysiology. Am J Physiol Renal Physiol 299: F689-F701, 2010.

16. Möller CC, Wei C, Altintas MM, Li J, Greka A, Ohse T, Pippin JW, Rastaldi MP, Wawersik S, Schiavi S, et al: Induction of TRPC6 channel in acquired forms of proteinuric kidney disease. J Am Soc Nephrol 18: 29-36, 2007.

17. Yang H, Zhao B, Liao C, Zhang R, Meng K, Xu J and Jiao J: High glucose-induced apoptosis in cultured podocytes involves TRPC6-dependent calcium entry via the RhoA/ROCK pathway. Biochem Biophys Res Commun 434: 394-400, 2013. 
18. Li Z, Xu J, Xu P, Liu S and Yang Z: Wnt/ $/$-catenin signalling pathway mediates high glucose induced cell injury through activation of TRPC6 in podocytes. Cell Prolif 46: 76-85, 2013.

19. Liu BC, Song X, Lu XY, Li DT, Eaton DC, Shen BZ, Li XQ and Ma P: High glucose induces podocyte apoptosis by stimulating TRPC6 via elevation of reactive oxygen species. Biochim Biophys Acta 1833: 1434-1442, 2013.

20. Kuwahara K, Wang Y, McAnally J, Richardson JA, Bassel-Duby R, Hill JA and Olson EN: TRPC6 fulfills a calcineurin signaling circuit during pathologic cardiac remodeling. J Clin Invest 116: 3114-3126, 2006.

21. Nishida M, Onohara N, Sato Y, Suda R, Ogushi M, Tanabe S, Inoue R, Mori Y and Kurose H: Galpha12/13-mediated up-regulation of TRPC6 negatively regulates endothelin-1-induced cardiac myofibroblast formation and collagen synthesis through nuclear factor of activated T cells activation. J Biol Chem 282: 23117-23128, 2007.

22. Onohara N, Nishida M, Inoue R, Kobayashi H, Sumimoto H, Sato Y, Mori Y, Nagao T and Kurose H: TRPC3 and TRPC6 are essential for angiotensin II-induced cardiac hypertrophy. EMBO J 25: 5305-5316, 2006.

23. Jia Y, Zhou J, Tai Y and Wang Y: TRPC channels promote cerebellar granule neuron survival. Nat Neurosci 10: 559-567, 2007.

24. Rao A, Luo C and Hogan PG: Transcription factors of the NFAT family: Regulation and function. Annu Rev Immunol 15: 707-747, 1997.

25. Wang Y, Jarad G, Tripathi P, Pan M, Cunningham J, Martin DR, Liapis $\mathrm{H}$, Miner JH and Chen F: Activation of NFAT signaling in podocytes causes glomerulosclerosis. J Am Soc Nephrol 21: $1657-1666,2010$

26. Wang L, Chang JH, Paik SY, Tang Y, Eisner W and Spurney RF: Calcineurin $(\mathrm{CN})$ activation promotes apoptosis of glomerular podocytes both in vitro and in vivo. Mol Endocrinol 25: 1376-1386, 2011

27. Schlöndorff J, Del Camino D, Carrasquillo R, Lacey V and Pollak MR: TRPC6 mutations associated with focal segmental glomerulosclerosis cause constitutive activation of NFAT-dependent transcription. Am J Physiol Cell Physiol 296: C558-C569, 2009

28. Nijenhuis T, Sloan AJ, Hoenderop JG, Flesche J, van Goor H, Kistler AD, Bakker M, Bindels RJ, de Boer RA, Möller CC, et al: Angiotensin II contributes to podocyte injury by increasing TRPC6 expression via an NFAT-mediated positive feedback signaling pathway. Am J Pathol 179: 1719-1732, 2011.

29. Yu QT, Qi LW, Li P, Yi L, Zhao J and Bi Z: Determination of seventeen main flavonoids and saponins in the medicinal plant Huang-qi (Radix astragali) by HPLC-DAD-ELSD. J Sep Sci 30 1292-1299, 2007.

30. Qiu LH, Xie XJ and Zhang BQ: Astragaloside IV improves homocysteine-induced acute phase endothelial dysfunction via antioxidation. Biol Pharm Bull 33: 641-646, 2010.
31. Zhao J, Yang P, Li F, Tao L, Ding H, Rui Y, Cao Z and Zhang W: Therapeutic effects of astragaloside IV on myocardial injuries: Multi-target identification and network analysis. PLoS One 7: e44938, 2012.

32. Gui D, Huang J, Guo Y, Chen J, Chen Y, Xiao W, Liu X and Wang N: Astragaloside IV ameliorates renal injury in streptozotocin-induced diabetic rats through inhibiting NF- $\mathrm{KB}$-mediated inflammatory genes expression. Cytokine 61: 970-977, 2013.

33. Chen J, Gui D, Chen Y, Mou L, Liu Y and Huang J: Astragaloside IV improves high glucose-induced podocyte adhesion dysfunction via alpha3betal integrin upregulation and integrin-linked kinase inhibition. Biochem Pharmacol 76: 796-804, 2008.

34. Gui D, Guo Y, Wang F, Liu W, Chen J, Chen Y, Huang J and Wang N: Astragaloside IV, a novel antioxidant, prevents glucose-induced podocyte apoptosis in vitro and in vivo. PLoS One 7: e39824, 2012.

35. Livak KJ and Schmittgen TD: Analysis of relative gene expression data using real-time quantitative PCR and the 2(-Delta Delta C(T)) Method. Methods 25: 402-408, 2001.

36. Reiser J, Polu KR, Möller CC, Kenlan P, Altintas MM, Wei C, Faul C, Herbert S, Villegas I, Avila-Casado C, et al: TRPC6 is a glomerular slit diaphragm-associated channel required for normal renal function. Nat Genet 37: 739-744, 2005.

37. Mundel P, Reiser J, Borja AZM, Pavenstädt H, Davidson GR, Kriz W and Zeller R: Rearrangements of the cytoskeleton and cell contacts induce process formation during differentiation of conditionally immortalized mouse podocyte cell lines. Exp Cell Res 236: 248-258, 1997.

38. Wang Z, Wei X, Zhang Y, Ma X, Li B, Zhang S, Du P, Zhang X and Yi F: NADPH oxidase-derived ROS contributes to upregulation of TRPC6 expression in puromycin aminonucleoside-induced podocyte injury. Cell Physiol Biochem 24: 619-626, 2009.

39. Zhang H, Ding J, Fan Q and Liu S: TRPC6 up-regulation in Ang II-induced podocyte apoptosis might result from ERK activation and NF- $\mathrm{kB}$ translocation. Exp Biol Med (Maywood) 234: 1029-1036, 2009.

40. Wu H, Peisley A, Graef IA and Crabtree GR: NFAT signaling and the invention of vertebrates. Trends Cell Biol 17: 251-260, 2007.

41. Crabtree GR: Calcium, calcineurin, and the control of transcription. J Biol Chem 276: 2313-2316, 2001.

42. Li R, Zhang L, Shi W, Zhang B, Liang X, Liu S and Wang W: NFAT2 mediates high glucose-induced glomerular podocyte apoptosis through increased Bax expression. Exp Cell Res 319: 992-1000, 2013.

43. Reed JC: Proapoptotic multidomain Bcl-2/Bax-family proteins: Mechanisms, physiological roles, and therapeutic opportunities. Cell Death Differ 13: 1378-1386, 2006.

44. Kriz W, Gretz N and Lemley KV: Progression of glomerular diseases: Is the podocyte the culprit? Kidney Int 54: 687-697, 1998. 